ELKOM, Vol.13, No.1, Juli 2020, pp. 121 - 133

p-ISSN : 1907-0012 (print)

e-ISSN : 2714-5417 (online)

http://ejurnal.stekom.ac.id/index.php/home

- page 121

\title{
PEMANFAATAN NATURAL LANGUAGE PROCESSING DAN PATTERN MATCHING DALAM PEMBELAJARAN MELALUI GURU VIRTUAL
}

\author{
Migunani ${ }^{1}$, Kevin Aditama $^{2}$ \\ ${ }^{1}$ Sistem Informasi STMIK ProVisi Semarang \\ migunani@provisi.ac.id \\ 2Sistem Informasi STMIK ProVisi Semarang \\ adhitamakevin@ymail.com
}

\section{ARTICLE INFO}

Article history:

Received 30 Mei 2020

Received in revised form 2Juni2020

Accepted 10Juli 2020

Available online 17 Juli 2020

\begin{abstract}
Virtual teachers are devices or agents with the function of replacing the role of humans (teachers) with their teaching skills. The virtual teacher also has a function as task facilitator and is presented during training, especially when the teacher is actually not present. The virtual teacher's objectivity is carried out by explaining the subject matter in a virtual environment, for example, virtual independent learning. In the western world, virtual schools are quite widely applied, especially to students who are homeschooling. In a virtual school, all materials, assignments and grades are accessed via the internet. The virtual teacher concept refers to a device that provides guidance and practice. Teachers who are equipped with interactive agent functions that can provide direction and feedback in order to improve student abilities. By utilizing natural language processing (NLP) and pattern matching to help students learn alone without being accompanied by a teacher. NLP is used as a learning tool as outlined in the text of the sentence as part of the learning material which is done virtually. Meanwhile, pattern matching is used to group the questions asked so that the computer can gain an understanding of the questions posed by students. This grouping aims to solve problems with different word order which basically have different meanings. The teacher has the facility to make material, make questions, and answer student questions. A teacher can add knowledge about the database to enrich the source of knowledge for students.
\end{abstract}

Keywords: Virtual Teacher, Learning, Natural Language Processing, Pattern Matching.

\section{PENDAHULUAN}

Pemerintah telah mengimplementasikan kurikulum 2013 untuk pendidikan menengah dan kejuruan. Pelajaran pada kurikulum 2013 lebih menekankan pada kemampuan untuk analisis. Hal ini kadangkala menyulitkan beberapa siswa dalam mempelajari materi pelajaran terutama matematika dan ilmu pengetahuan alam. Tidak sedikit orang tua murid berharap anak mereka memiliki pembimbing untuk mengajarkan materi pelajaran matematika dan ilmu pengetahuan alam terutama saat berada di luar sekolah. Sumber belajar siswa diperoleh melalui guru di sekolah. Materi belajar dapat ditransformasikan dalam sistem pembalajaran virtual oleh seorang guru. Dengan cara ini fungsi seorang guru dapat dibantu melalui guru virtual sehingga siswa dapat belajar mandiri terutama diluar sekolah dengan berbantuan guru virtual.

Guru virtual adalah perangkat atau agen yang bekerja di dalam suatu lingkungan (pendidikan) dengan fungsi menggantikan peran manusia (guru) dengan ketrampilan manual (mengajar) yang dimilikinya. Guru virtual juga mempunyai fungsi sebagai fasilitator tugas. Guru virtual biasanya dihadirkan di saat pelatihan, terutama saat guru sesungguhnya tidak hadir. Obyektivitas guru virtual yaitu menjelaskan sesuatu. Salah satu contoh guru virtual yang pernah diujicoba yaitu sistem pelatihan pilot. Kegiatan ini melibatkan 24 partisipan untuk menguji kemampuan guru virtual dalam menjelaskan latihan menggerakkan pesawat (Tang et all, 1998).

Received November 23, 2019; Revised November 29, 2019; Accepted Desember 12, 2019 
Natural language processing (pemrosesan/ pengolahan bahasa alami) adalah metode yang memproses input teks menjadi kata-kata kunci jawaban user (Hartanto dkk, 2013:35). Tahapan pemrosesan kata pada guru virtual untuk mendapatkan maksud atau makna kata menggunakan Natural Language Processing dilakukan dengan tiga tahapan. Tahap tokenizing digunakan untuk pemecahan kalimat menjadi kumpulan kata. Filtering untuk menghapus kata depan dan kata sambung dari kumpulan kata yang masuk. Sedangkan stemming digunakan menghapus imbuhan. Sedangkan analizing digunakan untuk analisa tingkat keterhubungan antar kata untuk memahami kumpulan kata yang dimaksud.

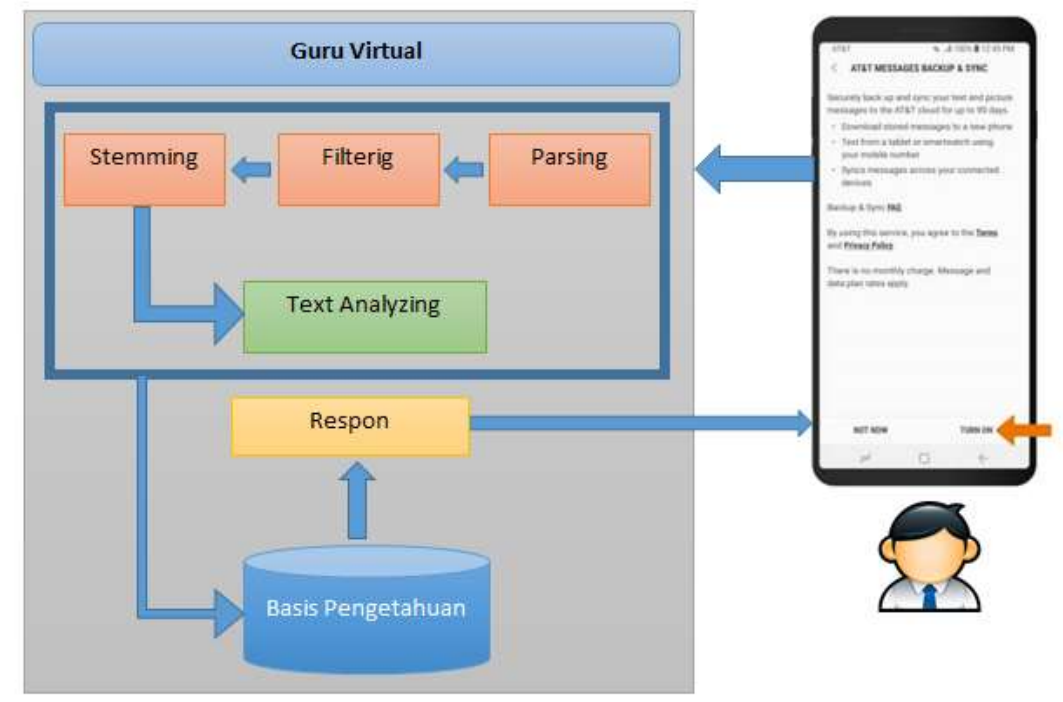

Gambar 1. Skema Guru Virtual

Pattern Matching adalah metode pencocokan pola yang digunakan dalam kecerdasan buatan (Ribalta, 2014). Dalam ilmu komputer, pattern matching digunakan untuk memeriksa urutan token yang ada di dalam suatu kalimat. Contoh dari pattern matching yaitu sequence pattern. Dalam sequence pattern, pencarian pola dilakukan menggunakan menggunakan reguler expression dan algoritma backtracking.

\section{TINJAUAN PUSTAKA}

\subsection{Guru Virtual}

Guru virtual adalah perangkat atau agen yang bekerja di dalam suatu lingkungan (pendidikan) dengan fungsi menggantikan peran manusia (guru) dengan ketrampilan manual (mengajar) yang dimilikinya. Guru virtual juga mempunyai fungsi sebagai fasilitator tugas. Guru virtual biasanya dihadirkan di saat pelatihan, terutama saat guru sesungguhnya tidak hadir. Obyektivitas guru virtual yaitu menjelaskan sesuatu. Guru virtual yang pernah diujicoba yaitu sistem pelatihan bagi pilot. Kegiatan ini melibatkan 24 partisipan untuk menguji kemampuan guru virtual dalam menjelaskan latihan menggerakkan pesawat (Tang et all, 1998). Guru virtual dihadirkan dalam lingkungan virtual sepertihlanya sekolah virtual. Lingkungan virtual dianggap lebih murah dan aman daripada lingkungan nyata ketika berhubungan dengan praktek (Tang et all, 1998). Di dunia barat, sekolah virtual cukup banyak diterapkan terutama kepada para siswa yang melakukan homeschooling.

Pada sekolah virtual, semua materi, tugas dan nilai diakses melalui internet. Sebenarnya administrator bisa mencarikan guru untuk melakukan kegiatan belajar mengajar secara langsung di internet. Namun biasanya tidak ditemukan guru yang tidak dapat melakukan hal tersebut dengan alasan keterbatasan waktu untuk mengajar secara langsung. Konsep guru virtual mengarah pada perangkat yang menyediakan bimbingan dan latihan. Guru virtual dilengkapi dengan fungsi agen interaktif yang dapat memberikan arahan maupun umpan balik dalam rangka peningkatan kemampuan siswa. Dalam studi yang lebih luas, guru virtual diharapkan juga dapat mendemonstrasikan strategi serta memberikan rasa kegiatan belajar mengajar yang nyata saat membimbing siswa (Tang et all, 1998).

\subsection{Chat Bot}

Chatbot adalah salah satu sistem cerdas yang dihasilkan dari Pemrosesan Bahasa Alami atau Natural Language Processing (NLP) yang merupakan salah satu cabang dari Kecerdasan Buatan atau Artificial Intelligence (AI). Chatbot memungkinkan manusia dapat berkomunikasi dengan mesin menggunakan

ELKOM Vol. 12, No. 2, Desember 2019: $1-9$ 
perantaraan bahasa alami (Setiaji, 2013). Setiaji membuat gambaran algoritma chatbot berbasis AIML seperti pada gambar di atas. Dari gambar tersebut terlihat bahwa main interpreter menerima masukkan dari user (stimulus), lalu mengidentifikasi kategorinya. Kemudian dilanjutkan lagi dengan pencarian template yang sesuai..

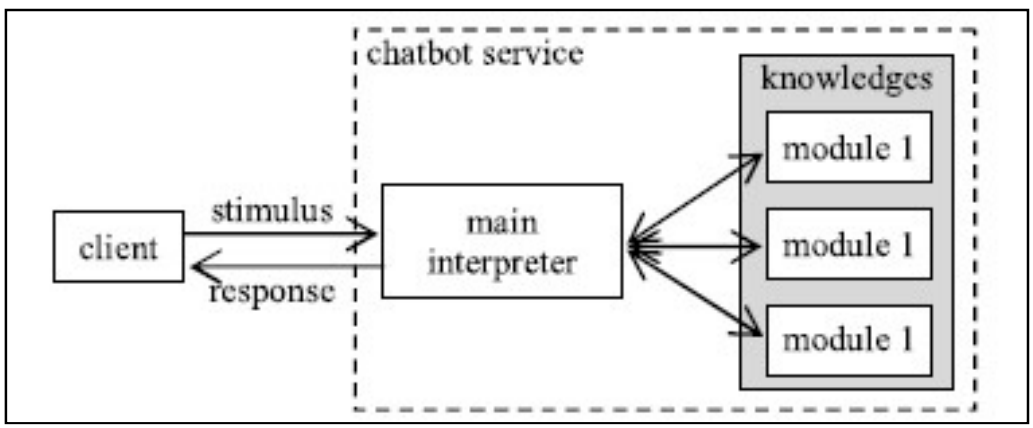

Gambar 2. Diagram Chatbot

Fokus perancangan dari chatbot tersebut adalah main interpreter yang di dalamnya terdapat beberapa sub proses.

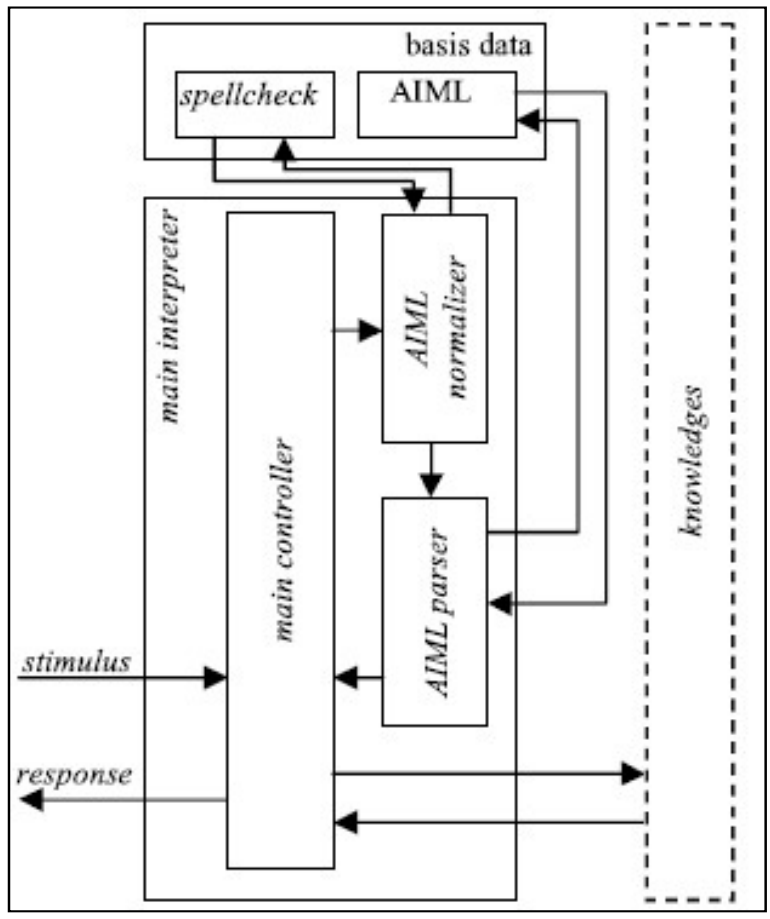

Gambar 3. Main Interpreter

Pada gambar menjelaskan rancangan main interpreter yang terdiri dari: (1) Main controller sebagai access point yang bertugas menerima stimulus dari client, mempersiapkan response, dan mengirimkannya kembali kepada client. (2) AIML normalizer Bertugas menormalkan stimulus sebelum diproses lebih lanjut oleh AIML parser. (3) AIML parser Stimulus yang sudah dinormalkan di AIML normalizer kemudian dilemparkan ke AIML parser untuk diolah lebih lanjut.

\subsection{Natural language processing}

Natural language processing (pemrosesan/ pengolahan bahasa alami) adalah metode yang memproses input teks menjadi kata-kata kunci jawaban user. (Hartanto dkk, 2013:35). Pengolahan Bahasa Alami 
merupakan cabang dari ilmu komputer dan linguistik yang membahas tentang interaksi antara manusi dengan komputer menggunakan bahasa alami (bahasa manusia). Dalam hal ini agar suatu komputer memahami bahasa alami, ia harus memiliki pengetahuan tentang bahasa almami itu sendiri baik dari segi kata yang digunakan, arti dari kata tersebut, fungsi kata dari sebuah kalimat dan bagaimana dari kata-kata tersebut dapat membentuk sebuah kalimat. Bahasa alami yang dimaksudkan di sini yaitu pesan yang ingin dikomunikasikan oleh manusia baik secara lisan maupun tulisan.

Dalam melakukan pengolahan bahasa alami, sistem membutuhkan beberapa komponen untuk menganalisis makna kalimat.

1. Parser

sistem mengambil kata-kata yang telah di-input oleh user, lalu mengelompokkannya berdasarkan gramatikal. Dalam skripsi ini, penulis membaginya menjadi subject, verb, adv, noun, adj, conj, atau ip.

2. Sistem Representasi Pengetahuan

Sistem menganalisis kumpulan kata tersebut guna menentukan maknanya. Dalam skripsi ini, penulis menyebut makna tersebut sebagai "intention".

3. Output Translator

Setelah melakukan analisis, sistem memberikan balasan kepada pengguna. Output dapat berupa bahasa alami atau output lainnya.

4. Pattern Matching

Pattern Matching adalah metode pencocokan pola yang digunakan dalam kecerdasan buatan (Ribalta, 2014). Dalam ilmu komputer, pattern matching digunakan untuk memeriksa urutan token yang ada di dalam suatu kalimat. Salah satu kegunaan pattern matching adalah untuk mencari komponen pola yang cocok, kemudian menggantinya dengan urutan token lainnya. Contoh dari pattern matching ialah sequence pattern. Dalam sequence pattern, pencarian pola terjadi dengan menggunakan reguler expression (regex) dan algoritma backtracking.

Selain reguler expression, pencarian pola kalimat dapat dilakukan dengan tree patterns. Tree patterns digunakan dalam beberapa bahasa pemrograman sebagai alat umum untuk memproses data berdasarkan strukturnya, misalnya, Haskell, ML, Scala dan Mathematica. Bahasa pemrograman tersebut memiliki sintaks khusus untuk mengekspresikan tree patterns dan konstruksi bahasa untuk eksekusi bersyarat dan pengambilan nilai berdasarkan itu. Dalam hal kesederhanaan dan efisiensi, penggunaan reguler expression (regex) masih lebih bagus daripada tree patterns.

\section{METODE PENGEMBANGAN SISTEM}

Penelitian menggunakan metode research and development (R\&D) Penelitian diawali dengan pengumpulan data untuk memperoleh data penelitian dan requirement dalam perancangan sistem guru virtual. Dengan menerapkan pemrosesan bahasa alami (natural language processing) dan kesesuaian pola (pattern matching) pada susunan kalimat yang digunakan pada antarmuka maka sistem maka fungsi guru virtual dapat terapkan.

3.1. Metode Pengumpulan Data

Metode pengumpulan data dilakukan melalui wawancara dengan guru dan siswa terkait kesulitan yang dihadapi siswa dalam belajar dan materi pelajaran yang dirasa sulit dipahami untuk dipelajari. Mata pelajaran Ilmu pengetahuan dan khususnya mata pelajaran matematika memiliki tingkat kusulitan tiggi. Selain wawancara juga dilakukan observasi dilapangan dengan melakukan pengamatan kegiatan belajar mengajar yang berlangsung. Dari hasil pengamatan tersebut diperoleh gambaran tentang bagaimana sebaiknya cara kerja sistem guru virtual yang sesuai dengan pendekatan yang sedekat mungkin dengan proses belajar mengajar antara guru dengan siswa di sekolah. Studi pustaka juga dilakukan melalui sumber-sumber pustaka primen dan sekunder yang relefan. Sumber-sumber pustaka primer dari materi pembelajaran siswa dan buku pegangan guru-guru dalam mengajar. Sedangkan sumber pustaka sekunder diperoleh dari jurnal ilmiah. Kedua jenis pustaka sebagai dasar penyusunan materi dan soal-soal sebagai knowledge base guru virtual.

3.2. Pemodelan Sistem Guru Virtual

Pemodelan sistem guru virtual menggunakan pendekatan berorientasi objek dengan menggambarkan model sistem menggunakan univfied modelling language (UML). Model sistem untuk merepresentasikan proses dan aktivitas didalam sistem, relasi antara aktor, objek dan class. Model awal UML menggambarkan business usecase untuk memperoleh gambaran proses level teratas dari sistem.

ELKOM Vol. 12, No. 2, Desember 2019: 1 -9 


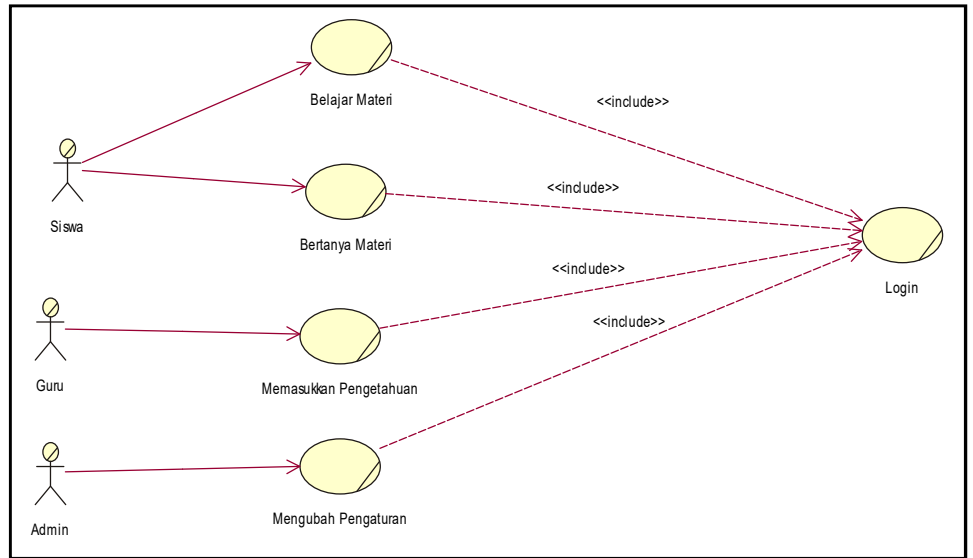

Gambar 4. Diagram Business Use Case Guru Virtual

Terdapat tiga aktor yang berperan dalam dalam proses bisnis pada sistem guru virtual yaitu siswa, guru, dan admin sistem. Siswa berperan sebagai aktor untuk melakukan interaksi dengan guru virtual dengan memberikan pertanyaan. Guru merupakan aktor yang berperan membuat basis pengetahuan kedalam sistem guru virtual dalam bentuk pengetahuan teori berupa taks maupun pengetahuan matematis berupa formula ke dalam basis pengetahuan guru virtual. Admin merupakan aktor yang berperan mengelola sistem guru virtual sebagai administrator aplikasi. Kegiatan belajar siswa dapat meliputi tanya jawab dengan guru virtual dan membaca materi pelajaran. Guru dapat memodifikasi materi melalui mode perekayasa pengetahuan. Jenis materi yang dapat dimasukkan oleh guru terdiri dari materi teori maupun hitungan. Admin dapat mengubah pengaturan aplikasi guru virtual melalui mode administrator. Jenis pengaturan yang dapat dilakukan oleh admin meliputi pengaturan siswa dan guru, pemilihan template, pengolahan data pengguna, dan pengaturan izin registrasi.

\subsection{Diagram Activity Guru Virtual}

Guru virtual melakukan parsing untuk mengambil kata-kata kunci pertanyaan hitungan. Kata-kata kunci yang dihasilkan dari parsing tadi memuat variabel yang diketahui dan ditanyakan pada soal. Nilai dari variabel yang diketahui digunakan oleh guru virtual untuk mencari nilai dari variabel yang ditanyakan pada soal.

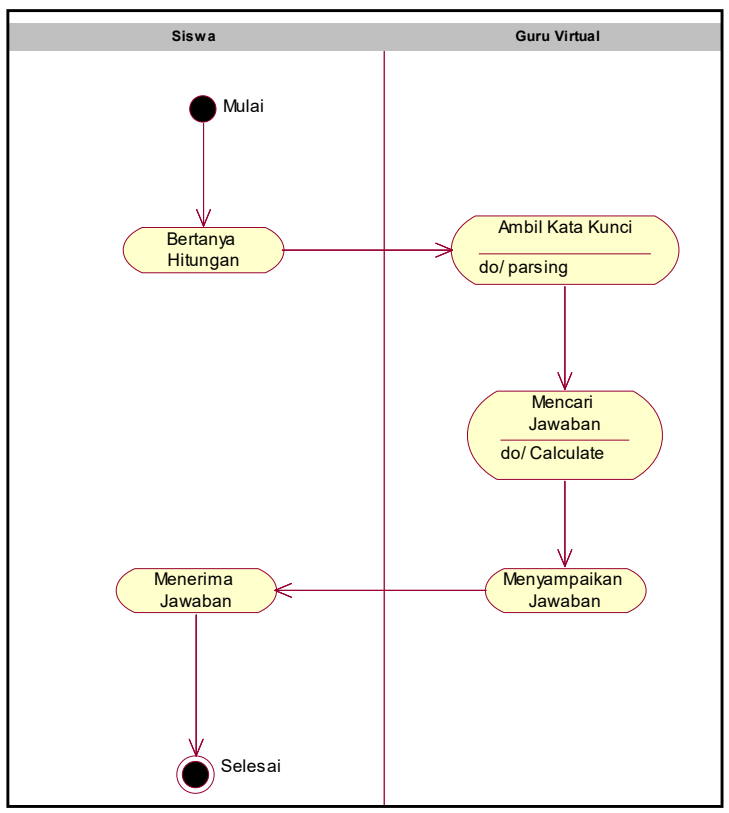

Gambar 5. Diagram Activity Guru Virtual Memparsing Pertanyaan Siswa 
Ketika siswa menanyakan soal teori, guru virtual menganalisis pertanyaan tersebut menggunakan algoritma NLP. Ada 3 proses di dalam algoritma NLP, yaitu:

1. Tokenization : memecah kalimat pertanyaan menjadi array berisi kumpulan kata.

2. Filtering : menghapus kata depan dan kata sambung dari array agar pencarian menjadi lebih valid.

3. Stemming : menghapus imbuhan pada tiap kata yang berpotensi menyebabkan gagalnya pencarian.

Dari proses NLP akan diperoleh kumpulan kata kunci. Kata-kata kunci tersebut dicari di basis data untuk ditemukan materi mana yang mengandung kata kunci paling banyak. Materi tersebutlah yang ditampilkan kepada siswa sebagai bentuk jawaban atas pertanyaan siswa.

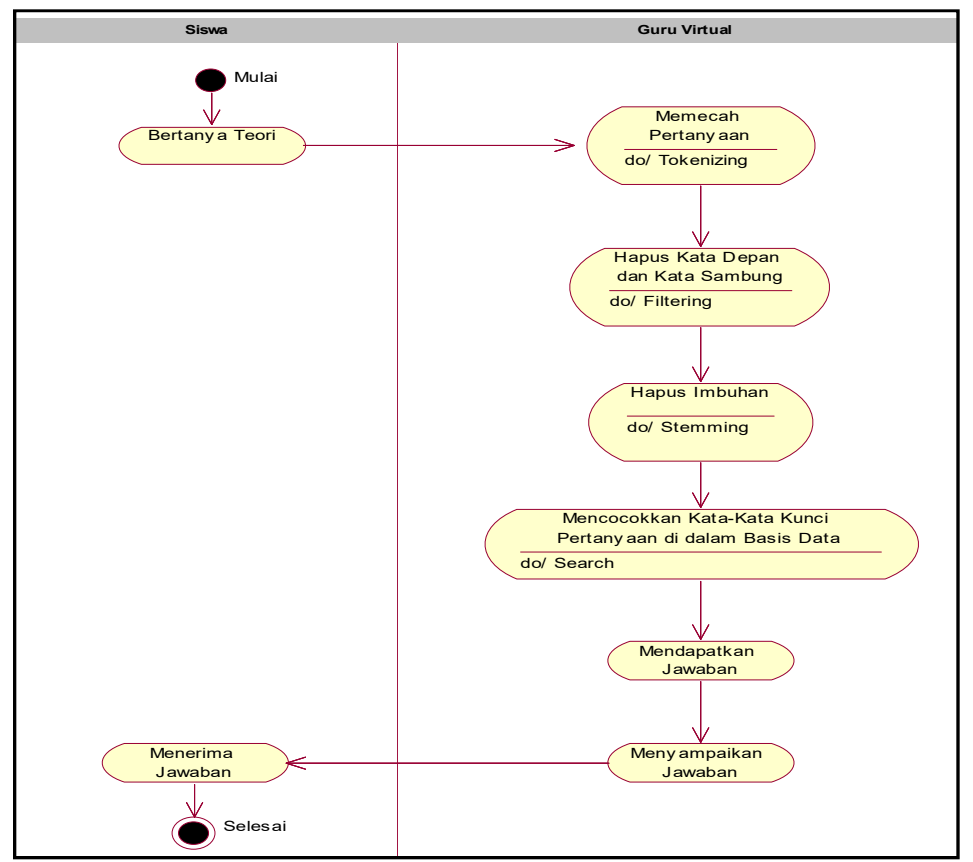

Gambar 6. Diagram Activity Tahapan Memparsing Pertanyaan Siswa

3.5. Perancangan Antarmuka Guru Virtual

Desain halaman percakapan guru virtual pada desktop terdiri dari sidebar, percakapan, dan textarea. Pada sidebar tercantum nama guru virtual, versi guru virtual, nama pengguna saat ini, dan link logout. Konten percakapan berisi percakapan antara guru virtual dan pengguna. Sedangkan textarea digunakan oleh siswa untuk mengetikkan pertanyaan.

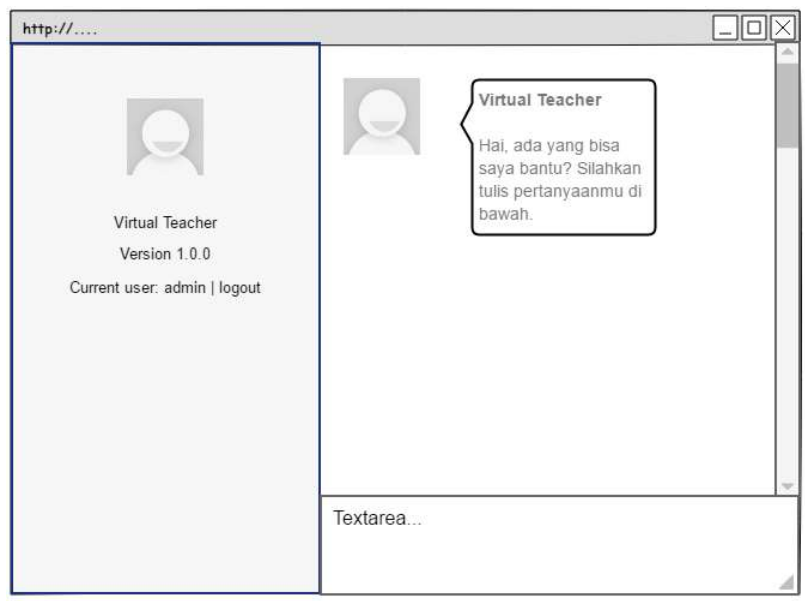

Gambar 7. Desain Halaman Chatbot

ELKOM Vol. 12, No. 2, Desember 2019: $1-9$ 


\section{HASIL DAN PEMBAHASAN}

4.1. Hasil Pengembangan Sistem

4.1.1. Siswa Bertanya Soal Operasi Hitung Campuran

Ketika guru virtual mendeteksi bahwa siswa bertanya soal operasi hitung campuran, maka guru virtual akan menyelesaikan soal tersebut sesuai dengan aturan BODMAS (BODMAS rule), yaitu menyelesaikan operasi operasi hitung campuran dengan urutan Brackets (tanda kurung), Order (urutan), Division (pembagian), Multiplication (perkalian), Addition (penjumalahan), dan Substract (pengurangan). Proses penyelesaian soal operasi hitung campuran dengan aturan BODMAS dilakukan menggunakan algoritma backtracking. Setelah jawaban berhasil ditemukan, guru virtual menampilkan jawaban soal beserta dengan langkah penyelesaiannya. Guru virtual dilengkapi dengan fitur Mathjax agar siswa lebih nyaman membaca simbol dan bentuk operator matematika yang ditampilkan oleh guru virtual.

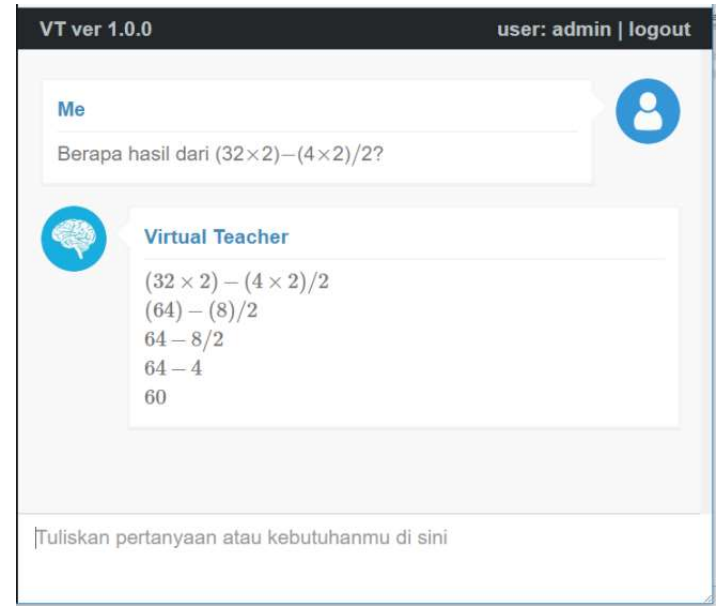

Gambar 8. Soal Operasi Hitung Campuran

\subsubsection{Tampilan saat Siswa Bertanya Soal Analisis}

Soal analisis berupa pertanyaan (baik hitungan atau bukan) yang membutuhkan penalaran untuk menyelesaikannya. Untuk memastikan bahwa soal yang ditanyakan oleh siswa adalah soal analisis, penulis menggunakan pattern matching. Dengan pattern matching, guru virtual dapat mengetahui apakah pola susunan kata pada kalimat pertanyaan siswa sama dengan pola susunan kata pada salah satu modul soal analisis guru virtual. Jika iya, maka guru virtual akan menyelesaikan soal tersebut menggunakan modul penyelesaian soal analisis yang sesuai dengan jenis soal tersebut. Saat ini aplikasi guru virtual memilliki 2 modul penyelesaian soal analisis yaitu fpb dan kpk.

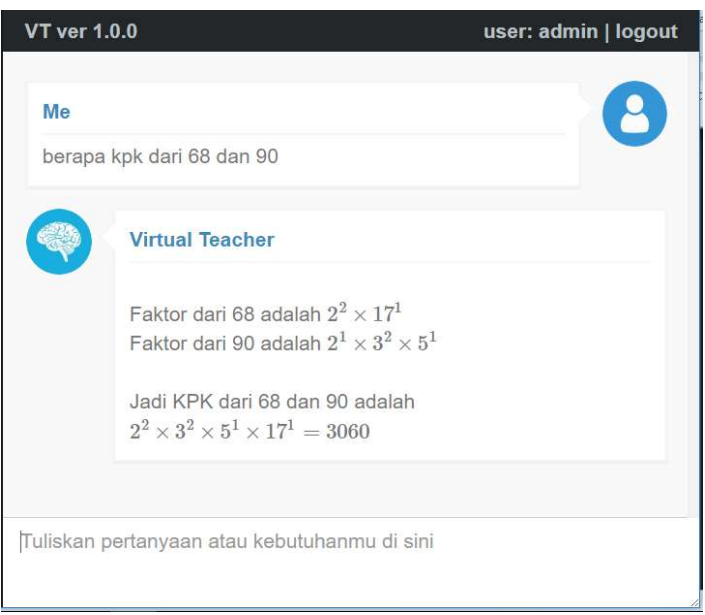

Gambar 9. Siswa Bertanya Soal Analisis Formula 
4.1.3. Siswa Bertanya Soal Hitungan

Soal hitungan yaitu segala macam pertanyaan yang dapat diselesaikan menggunakan rumus. Ketika siswa bertanya soal hitungan, guru virtual akan menjawab soal tersebut dengan urutan diketahui, ditanya, dan jawab. Apabila variabel yang ditanyakan belum bersatuan baku, maka guru virtual akan mengubah variabel tersebut ke dalam bentuk satuan baku terlebih dahulu.

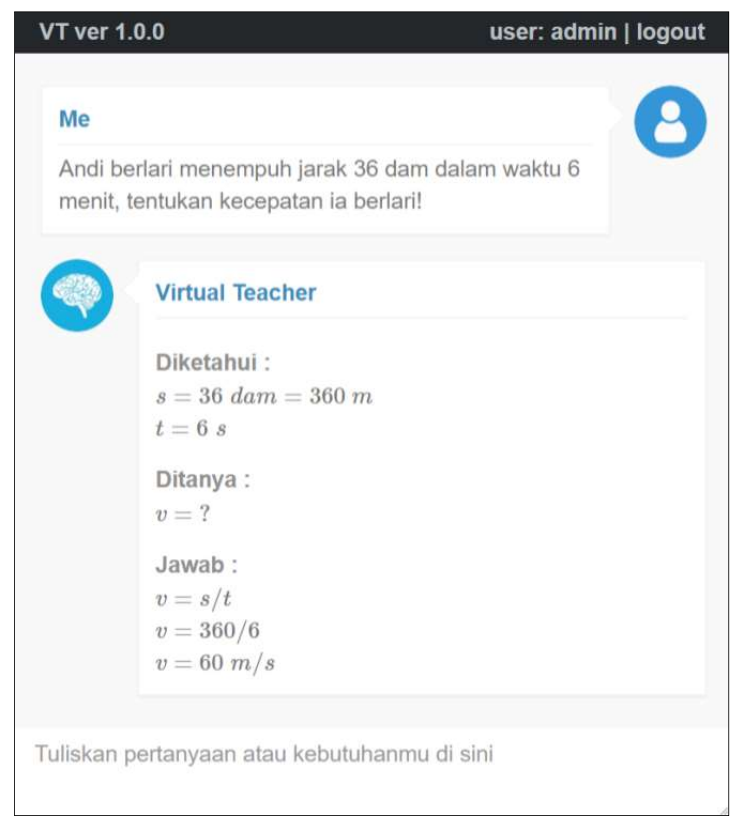

Gambar 10. Siswa Bertanya Soal Hitungan

4.1.4 Tampilan saat Siswa Bertanya Soal teori

Untuk dapat menjawab pertanyaan siswa, guru virtual akan memproses kalimat pertanyaan siswa di dalam NLP Layer. Proses tersebut meliputi tokenization, filtering, dan stemming.

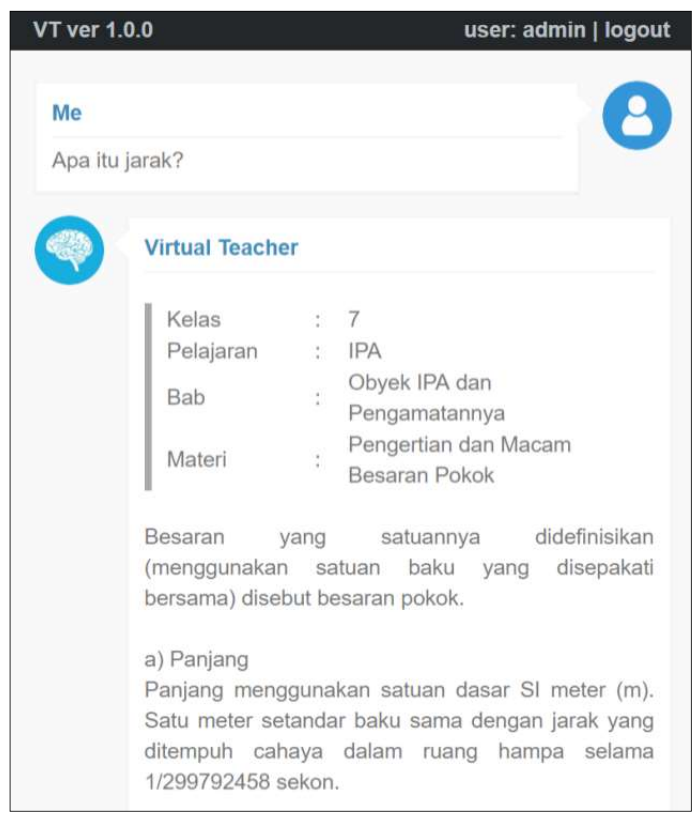

ELKOM Vol. 12, No. 2, Desember 2019: 1-9 
4.1.5 Tampilan saat Siswa Minta Dibuatkan Soal Hitungan

Ketika siswa minta dibuatkan soal hitungan, guru virtual akan men-generate soal dari template pertanyaan yang tersimpan di dalam basis data. Template pertanyaan dapat dibuat oleh guru sekolah. Semakin banyak template pertanyaan, maka jenis soal yang ditampilkan kepada siswa juga makin bervariasi. Tiap template pertanyaan hitungan memiliki variabel besaran, nilai, dan satuan. Variabel nilai yang dimasukkan oleh guru bukan berupa angka melainkan simbol besaran nilai tersebut dengan tambahan tanda dollar (\$) di awalnya. Saat template pertanyaan digunakan untuk membuat soal, guru virtual akan mengganti variabel nilai dengan angka sembarang sedemikian rupa sehingga jawaban dari soal tersebut berupa bilangan bulat. Hal ini bertujuan agar siswa tidak kesulitan menjawab soal. Proses pencarian angka pengganti variabel nilai dilakukan menggunakan fungsi rekursif.

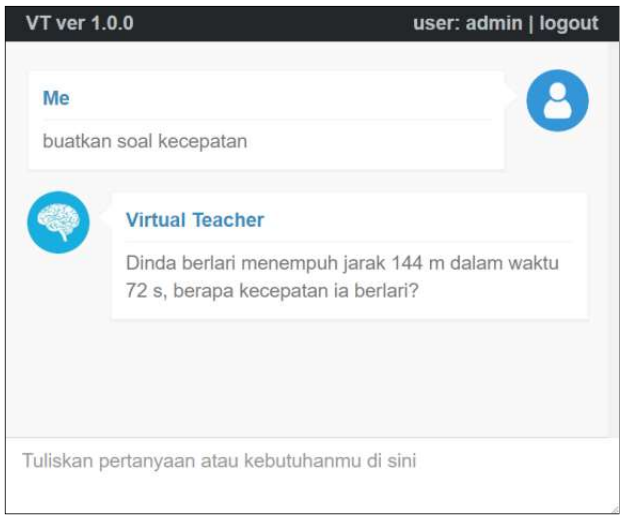

Gambar 32. Siswa Minta Dibuatkan Soal Hitungan

4.1.6 Siswa Menjawab Soal Hitungan Guru Virtual

Guru virtual menyimpan secara sementara pertanyaan yang ia buat sendiri ke dalam folder 'tmp'. Dengan menggunakan algoritma yang sama yang digunakan untuk menjawab soal hitungan, guru virtual dapat mencari jawaban atas pertanyaan yang ia buat sendiri. Dengan demikian, ketika siswa menjawab pertanyaan guru virtual, guru virtual dapat mengecek apakah jawaban siswa betul atau salah sekaligus memberikan langkah penyelesaian untuk soal yang dibuatnya sendiri tersebut.

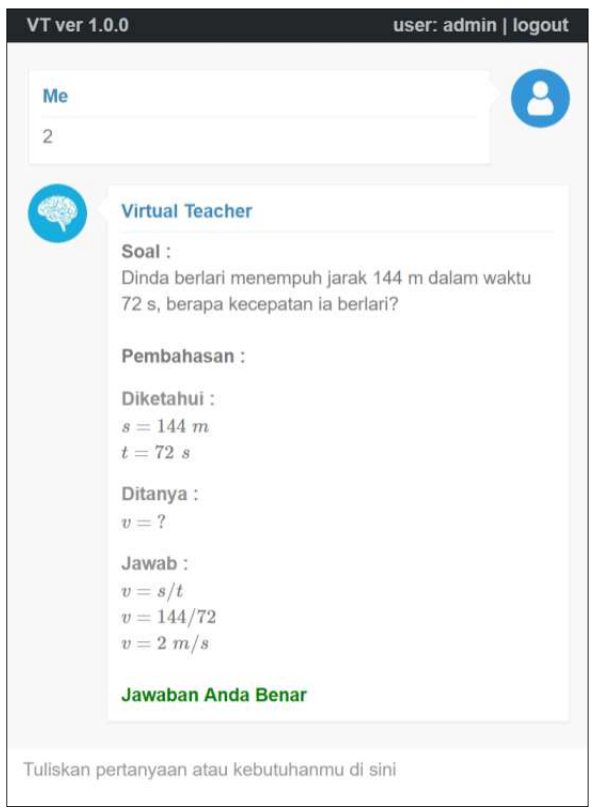




\subsubsection{Tampilan saat Siswa Minta Dibuatkan Soal Teori}

Saat siswa minta dibuatkan soal teori, guru virtual akan mengambil secara acak kalimat pernyataan yang ada di dalam basis data menggunakan fungsi random. Sebelumnya, guru virtual mencocokkan terlebih dahulu materi yang ada di dalam basis data dengan materi yang diinginkan oleh siswa. Proses ini dilakukan menggunakan pattern matching. Setelah kalimat pernyataan berhasil diperoleh, guru virtual akan mengubah kalimat pernyataan tersebut menjadi kalimat pertanyaan dengan menghilangkan kata-kata setelah kata adalah atau semacamnya.

\section{VT ver 1.0.0 user: admin | logout}

Me

buatkan soal bilangan bulat

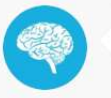

Virtual Teacher

Bilangan Cacah ialah ....

Tuliskan pertanyaan atau kebutuhanmu di sini

Gambar 54. Siswa Meminta Dibuatkan Soal Teori Oleh Guru Virtual

\subsubsection{Siswa Menjawab Soal Teori Guru Virtual}

Guru virtual menyimpan kalimat pernyataan yang ia gunakan untuk membuat soal ke dalam folder "tmp". Ketika siswa menjawab soal teori tadi, guru virtual akan memanggil kalimat pernyataan tersebut. Kemudian guru virtual mencocokkan jawaban siswa dengan kalimat pernyataan itu. Apabila ada banyak kemiripan, maka jawaban siswa dihitung benar.

\section{VT ver 1.0 .0 \\ user: admin | logout}

Me

bilangan bulat bulat positif dengan bilangan nol

Virtual Teacher

Jawaban untuk pertanyaan tadi adalah sebagai berikut:

Bilangan Cacah adalah bilangan bulat bulat positif dengan bilangan nol

Jawaban anda Benar

Tuliskan pertanyaan atau kebutuhanmu di sini

ELKOM Vol. 12, No. 2, Desember 2019 : 1 - 9 


\subsubsection{Siswa Meminta Ditampilkan Materi}

Gambar 6. Siswa Menjawab Soal Teori Guru Virtual

Berbeda dengan jawaban atas pertanyaan teori, tampilan rangkuman materi yang sajikan oleh guru virtual jauh lebih lengkap karena mencakup satu sub bab. Ketika guru virtual menjawab pertanyaan teori, dia hanya memberikan jawaban dan pembahasan yang relevan dengan pertanyaan. Namun ketika siswa meminta materi tertentu, maka guru virtual akan menampilkan semua materi terkait dengan materi yang diminta oleh siswa tersebut selama materi-materi yang lainnya masih dalam satu sub bab dengan materi yang yang diminta oleh siswa. Guru virtual juga menyediakan tombol print di akhir percakapan. Dengan demikian, siswa bisa mencetak rangkuman materi yang ditampilkan oleh guru virtual.
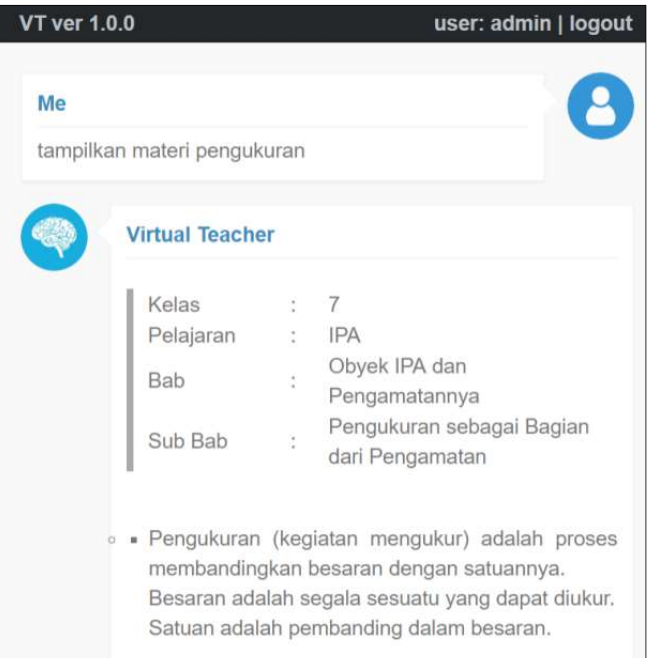

Gambar 16. Siswa Meminta Ditampilkan Materi

4.1.10. Tampilan Mode Perekayasa Pengetahuan

Mode ini hanya dapat dimasuki oleh guru dan admin. Mode ini digunakan untuk menambahkan pengetahuan baru ke dalam basis data guru virtual. Supaya dapat masuk ke mode ini, guru perlu mengetikkan kode "create new knowledge".

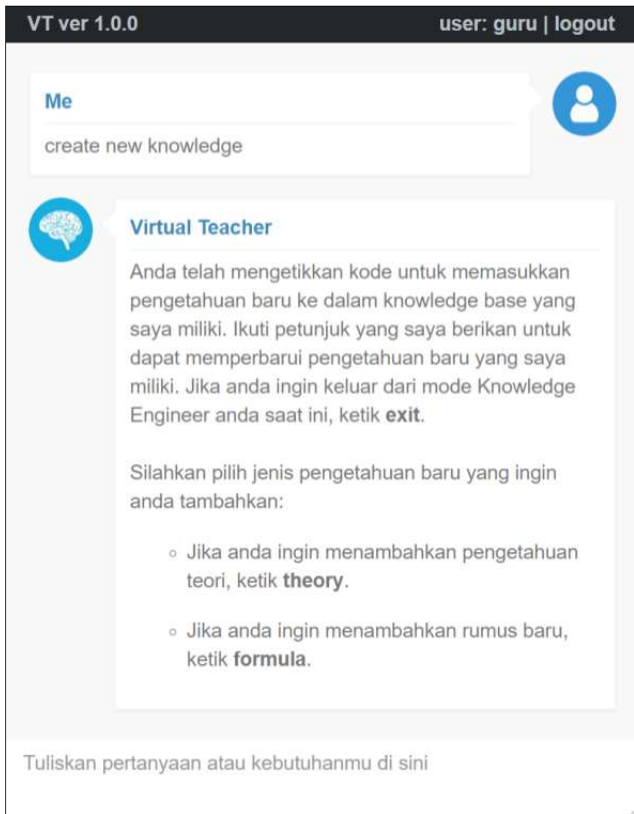


Gambar 17. Tampilan Mode Perekayasa Pengetahuan

4.1.11. Tampilan Mode Administrator

Mode administrator hanya bisa dimasuki oleh admin. Dalam mode ini, admin bisa mengubah pengaturan sistem. Untuk masuk ke mode ini, admin harus mengetikkan kode "set config".

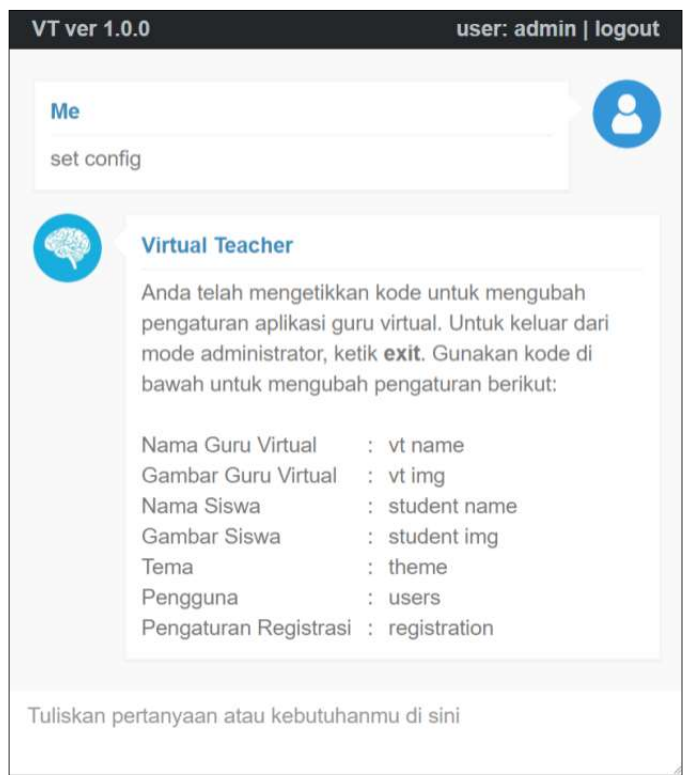

Gambar 18. Tampilan Mode Administrator

\section{KESIMPULAN}

5.1. Guru virtual menyediakan materi pelajaran

Aplikasi guru virtual dapat menyediakan materi pelajaran dengan merujuk dan meyesuakian menyesuaikan kurikulum 2013. Materi pelajaran dapat di minta siswa ke guru virtual untuk ditampilkan sesuai dengan permintaan. Siswa yang ingin belajar materi pelajaran tertentu, menuliskan perintah untuk meminta aplikasi menampilkan materi tersebut dengan mengetikkan "tampilkan materi [nama materi]". Agar isi materi selalu menyesuaikan dengan perkembangan kurikulum pendidikan terbaru, para guru dapat ikut memperbarui materi melalui mode Knowledge Engineer.

\subsection{Guru Virtual dapat membuatkan soal pelajaran}

Aplikasi guru virtual dapat membuatkan soal pelajaran sesuai kurikulum pendidikan. Bagi siswa yang ingin melatih kemampuannya dalam mengerjakan soal dapat meminta guru virtual untuk menyediakan soal dengan berkata "buatkan soal tentang [nama materi]".

5.3. Guru Virtual dapat menjawab pertanyaan pelajaran

Aplikasi guru virtual dapat menjawab pertanyaan pelajaran sesuai kurikulum pendidikan. Bagi siswa yang sedang mencari jawaban soal pada mata pelajaran tertentu, ia bisa menanyakan soal tersebut kepada guru virtual. Apabila pertanyaan tersebut berupa soal teori, guru virtual akan menjawab soal tersebut disertai dengan pembahasan. Apabila pertanyaan tersebut berupa soal hitungan, guru virtual akan menjawab soal tersebut disertai dengan langkah penyelesaian.

\section{DAFTAR PUSTAKA}

1. Anam, Khairil, Sehman. 2018. "Aplikasi Agen Cerdas untuk Pembelajaran Pemrograman Berorientasi Objek Berbasis Natural Language Processing (NLP)."

2. Gaol, Melva Lumban, Kristin L. Sitompul, dan Muhammad Zarlis. 2017. "Penerapan Algoritma

ELKOM Vol. 12, No. 2, Desember 2019: $1-9$ 
Backtracking Dalam Game Pencarian Kata Menggunakan Aksara Batak Toba." Seminar Nasional Teknologi Informatika (Semantika).

3. Hartanto, Harry, dan Inge Martina. 2013. "Sistem Wawancara Virtual untuk Penerimaan Mahasiswa Jurusan Teknik Informatika di ITHB dengan Metode Natural Language Processing.".

4. Hasyim, Nurlaila, Nur Aeni Hidayah, Sarwoto Wijoyo Latisuro. 2014. "Rancang Bangun Sistem Informasi Koperasi Berbasis Web pada Koperasi Warga Baru MTs N 17 Jakarta." STUDIA INFORMATIKA: JURNAL SISTEM INFORMASI 7.2.

5. Kusrini. 2006. Sistem Pakar, Teori dan Aplikasi. Yogyakarta: Andi.

6. Nila, Elisabet. 2016. "Rancang Bangun Aplikasi Chatbot Informasi Objek WIsata Kota Bandung dengan Pendekatan Natural Language Processing" KOMPUTA-Jurnal Komputer \& Informatika 4.1

7. Pressman, Roger S. 2002. Rekayasa Perangkat Lunak Pendekatan Praktisi. Yogyakarta : Andi.

8. Ribalta, Ruris. 2014. "Rancang Bangun Sistem Pembelajaran Menggunakan Chatbot dengan Algoritma Boyer-Moore”. Skripsi thesis. Riau:. Universitas Islam Negeri Sultan Syarif Kasim

9. Sadewo, Mas Adi Prasetyo. 2014. "Rancang Bangun Sistem Informasi Pemesanan Tiket Bus pada PO. Selamet”. Skripsi. Fakultas Teknologi Informasi Universitas STIKUBANK Semarang

10. Setiaji, Bayu, Ema Utami, Hanif Al Fatta. 2013. "Membangun Chatbot Berbasis AIML dengan Arsitektur Pengetahuan Modular." SEMNASTEKNOMEDIA ONLINE 1.1

11. Tang, Philip, R. Brent Gillespie, M. Sile O’Modhrain, David Zaretzky, Cuong Pham. 1998. "The virtual teacher". American Society of Mechanical Engineers.

12. Tolle, Herman, Aryo Pinandito, Agi Putra Kharisma. 2017. "Pengembangan Aplikasi Perangkat Bergerak". Malang: UB Press.

13. Yusuf, Irfan, Sri Wahyu Widyaningsih, Dewi Purwati. 2015. "Pengembangan Perangkat Pembelajaran Fisika Modern Berbasis Media Laboratorium Virtual Berdasarkan Paradigma Pembelajaran Abad 21 dan Kurikulum 2013." 